\title{
Plasmid Fusions Mediated by One End of $\operatorname{Tn} A$
}

\author{
By JOHN HERITAGE† AND PETER M. BENNETT* \\ University of Bristol, Department of Microbiology (Unit of Molecular Genetics), \\ The Medical School, University Walk, Bristol BS8 1TD, UK
}

(Received 25 September 1984 ; revised 4 December 1984)

\begin{abstract}
We have observed plasmid fusions in a $\operatorname{rec} A$ background mediated by a single end of $\operatorname{Tn} A$. These occur when transposase is provided either in cis or in trans. Insertions of the plasmid carrying the $\operatorname{Tn} A$ inverted repeat sequence occur at many sites in the target plasmid. The point of fusion on the plasmid carrying $\operatorname{Tn} A$ sequences always appears to be located in the region which carries the $\operatorname{Tn} A$ inverted repeat sequence. In contrast to the transposition of an intact $\operatorname{Tn} A$ element, plasmid fusions mediated by one end of $\operatorname{Tn} A$ are very rare events. The implications of our results for models of transposition are discussed.
\end{abstract}

\section{INTRODUCTION}

Transposition of the $\operatorname{Tn} A$ family of transposons involves the duplication of a discrete piece of DNA bounded by short, perfect or near-perfect inverted repeat sequences (IR sequences), and its insertion, apparently at random, into a non-homologous site in a target replicon, resulting in the formation of a transposition cointegrate (Gill et al., 1978). The reaction requires the presence of both of the IR sequences, since these define the limits of the element, and also requires a transposon-encoded diffusible product, transposase (Heffron et al., 1977). Resolution of cointegrate structures to generate transposition products requires a second transposon-encoded diffusible product, resolvase, which mediates a site-specific recombination between the duplicate copies of the res site of the transposon (Arthur \& Sherratt, 1979).

Recently it has been reported that derivatives of the $\operatorname{Tn} A$-related elements Tn21 (Avila et al., 1984) and Tn1721 (Motsch \& Schmitt, 1984) that possess only one end of the particular transposon are capable of mediating the formation of plasmid fusions in $\operatorname{rec} A$ strains provided that the appropriate transposase is also present. We now report $\operatorname{rec} A$-independent plasmid fusions mediated by a single end of $\operatorname{Tn} A$, and we compare products of this type of recombination with the transposition of an intact $\operatorname{Tn} A$ element.

\section{METHODS}

Bacterial strains and plasmids used. The Escherichia coli strains used were UB5201 (Pro- Met $^{-}$RecA $^{-} \mathrm{Nal}^{\mathrm{R}}$ ) (Bennett \& Richmond, 1976), JC6310 (His ${ }^{-}$Lys $^{-}$Trp $^{-}$RecA- Str ${ }^{R}$ ) (Bennett \& Richmond, 1976) and UB2272 (His ${ }^{-}$Lys $^{-}$Trp $^{-}$PolA $^{-}$Str $^{R}$ Rif $^{R}$ ) (Jenkins \& Bennett, 1978). The plasmids used are shown in Table 1.

Construction of plasmids $p U B 3032$ and pUB3033. Plasmids pUB3032 and pUB3033 were generated from a pACYC184 derivative, pUB2992 (H. M. Dodd, unpublished results), a plasmid that carries an analogue of the $\operatorname{Tn} A$ res site originating on the resistance plasmid R46 (Dodd \& Bennett, 1983), by transposition of $\operatorname{Tn} A$ to pUB2992 and subsequent site-specific recombination between the $\operatorname{Tn} A$ res site and the $\mathrm{R} 46$ res site analogue. In these particular plasmids the recombination resulted in deletion of all $\operatorname{Tn} A$ sequences from the res site to the right-hand IR sequence, in addition to plasmid sequences between the point of $\operatorname{Tn} A$ insertion and the $\mathrm{R} 46$ res site analogue. Hence each plasmid carries the $\operatorname{Tn} A$ transposase gene $\operatorname{tmp} A$, and the adjacent IR sequence IR(l)

† Present address: Department of Microbiology, The Old Medical School, University of Leeds, Leeds LS2 9JT, UK.

Ahbretiation: IR, inverted repeat. 


\section{Table 1. Plasmids}

The abbreviations used for plasmid nomenclature are those recommended by Novick et al. (1976).

$\begin{array}{ll}\text { Plasmid } & \text { Phenotype conferred } \\ \text { R388 } & \text { Tp Su Tra }{ }^{+} \text {IncW } \\ \text { pUB307 } & \text { Km Tc Tra IncP } \\ \text { pUB501 } & \text { Tp Su Tra }{ }^{+} \text {IncW } \\ \text { pBR322 } & \text { Ap Tc Tra } \\ \text { RSF1596 } & \text { Ap Tra } \\ \text { pUB2280 } & \text { Tp Tra IncW } \\ \text { pUB2284 } & \text { Tp Tra IncW } \\ \text { pUB3032 } & \text { Cm Tra- } \\ \text { pUB3033 } & \text { Cm Tra- } \\ \text { pUB3078 } & \text { Tp Tra IncW }\end{array}$

Reference or source

* Department of Microbiology, University of Bristol, UK.

Datta \& Hedges (1972)

Bennett et al. (1977)

Robinson et al. (1977)

Bolivar et al. (1977)

Heffron et al. (1977)

This paper (Fig. 1)

This paper (Fig. 1)

H. M. Dodd* (Fig. 1)

H. M. Dodd* (Fig. 1)

This paper

(Fig. 1), as well as the cat gene of pACYC184. In all cases the expression of the $\operatorname{tmpA}$ gene is assumed to be derepressed due to deletion of the $t m p R$ gene (Chou et al., 1979). The plasmids pUB3032 and pUB3033 were used as a source of transposase throughout these experiments.

Construction of pUB2280. Plasmid pUB2280 was generated in vitro from plasmid pUB1605, a PstI-generated deletion derivative of the $\mathrm{R} 388$ : : Tn 802 recombinant plasmid pUB1604 (Wallace et al., 1981), by circularizing the smaller of the two $B g / I I$ fragments. The deletion removed the genes needed for self-mediated transfer. Plasmid pUB2280 is $8 \mathrm{~kb}$ long, encodes trimethoprim resistance and carries $1000 \mathrm{bp}$, including the IR sequence, from the left-hand end of $\operatorname{Tn} A$ (Fig. 1).

Construction of pUB2284. Plasmid pUB2263 was isolated following transposition of a copy of Tn802 onto pUB501 (R388:: Tn802 bla) (Heritage \& Bennett, 1984). This transposition event resulted in a deletion which removed most, if not all, of the transfer functions encoded by pUB501, and regenerated, by transposon-encoded site-specific recombination, a functional copy of $\mathrm{Tn} 802$ at the site of the mutant transposon carried on pUB501. Plasmid pUB2284 was generated in vitro by circularizing the largest PstI fragment derived from pUB2263. Plasmid pUB2284 is $16 \mathrm{~kb}$ long, encodes trimethoprim resistance and carries $450 \mathrm{bp}$, including the IR sequence, from the right-hand end of $\operatorname{Tn} A$ (Fig. 1).

Construction of $p U B 3078$. Plasmid pUB3078, which was generated in vitro by circularizing the smaller of the two $B g / \mathrm{ll}$ fragments derived from $\mathrm{R} 388$, is $8 \mathrm{~kb}$ long and encodes trimethoprim resistance.

Antibiotic selection. Minimal salts agar supplemented with the appropriate growth requirements and $0.4 \%$ glucose was used as the solid growth medium into which antibiotics were incorporated (Bennett $\&$ Richmond, 1976). Antibiotics were used at the following concentrations: carbenicillin, $500 \mu \mathrm{g} \mathrm{ml}^{-1}$; chloramphenicol, $25 \mu \mathrm{g} \mathrm{ml}^{-1}$ : kanamycin, $30 \mu \mathrm{g} \mathrm{ml}^{-1}$; nalidixic acid, $25 \mu \mathrm{g} \mathrm{ml}^{-1}$; streptomycin, $100 \mu \mathrm{g} \mathrm{ml}^{-1}$; sulphonamide, $500 \mu \mathrm{g} \mathrm{ml}^{-1}$; tetracycline, as achromycin, $20 \mu \mathrm{g} \mathrm{ml}^{-1}$; and trimethoprim, $25 \mu \mathrm{g} \mathrm{ml}^{-1}$.

Conjugal transfer of plasmids. Plasmids were transferred in liquid matings as described by Bennett \& Richmond (1976), or on solid medium as described by Avila et al. (1984).

Tests for genetic linkage. Tests for genetic linkage of drug resistance determinants were made by toothpicking clones onto minimal salts agar, appropriately supplemented and containing one of the set of antibiotics to be tested.

Isolation of DNA. Isolation of plasmid DNA was by the method of Birnboim \& Doly (1979) or by the method of Wallace et al. (1981), as was convenient.

Restriction endonuclease analysis. Commercially available enzymes were used from a variety of sources. Digestions and agarose gel electrophoresis were performed as described by Grinsted et al. (1978).

Transformation. Transformation was by the method of Cohen et al. (1972), using the modifications of Humphries et al. (1976).

\section{RESULTS}

\section{Demonstration of TnA tnpA gene on $p U B 3032$ and $p U B 3033$}

Plasmids pUB3032 and pUB3033 were introduced by transformation into $E$. coli UB5201(RSF1596). RSF1596 (TnpA- Res $^{-}$TnpR ${ }^{-}$) is a plasmid which carries a deleted $\operatorname{Tn} A$ element but which retains a functional $\beta$-lactamase gene and both IR sequences. The deleted $\operatorname{Tn} A$ element on this plasmid must be complemented for transposase if it is to transpose. 


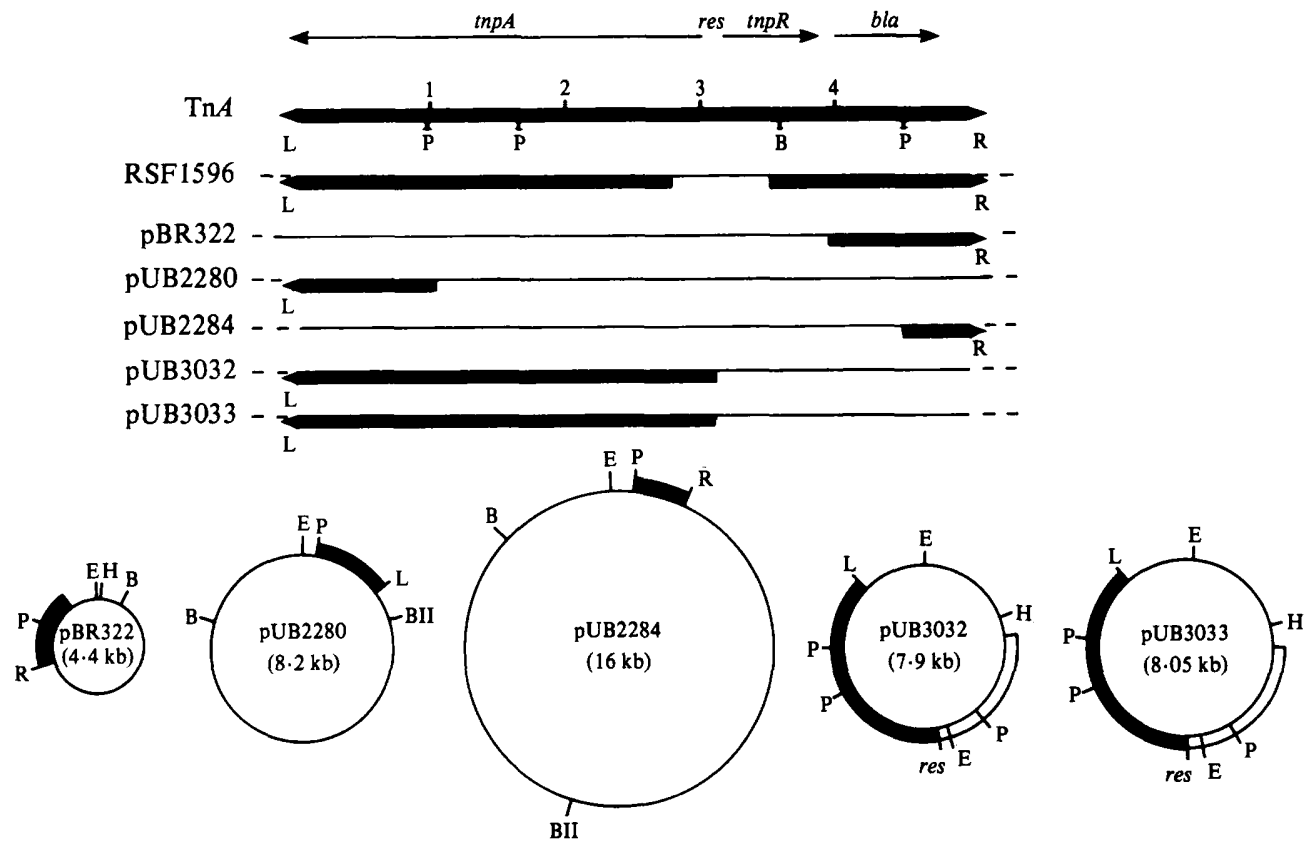

Fig. 1. Maps of $\operatorname{Tn} A$ derivatives used in this study, and of plasmids on which they reside. $L$ and $R$ denote the left- and right-hand IR sequences IR(l) and IR(r) respectively. On plasmids pUB3032 and pUB3033, the thin line denotes pACYC184 sequences, and the double lines denote sequences originally derived from plasmid R46. Tn $A$ sequences are shown as bold lines. B, BamHI; BII, BglII; E, EcoRI; H, Hind III; P, PstI.

Transposition generates cointegrate end products (Heffron et al., 1977). The IncP plasmid pUB307 was introduced by conjugation into $E$. coli UB5201(RSF1596, pUB3032) and UB5201(RSF1596, pUB3033). After allowing transposition products to accumulate (Wallace $e t$ al., 1981), E. coli UB5201(RSF1596, pUB3032, pUB307) and UB5201(RSF1596, pUB3033, pUB307) were each mated with $E$. coli UB2272, a PolA- strain in which RSF1596, pUB3032 and pUB3033 cannot replicate. In both experiments plasmid pUB307 transferred to $E$. coli UB2272 with a frequency of about $10^{-1}$, while the frequency of transfer of carbenicillin resistance was $2 \times 10^{-4}$, and that of chloramphenicol resistance was $4.5 \times 10^{-6}$. Genetic analysis of the transposition products revealed that the carbenicillin resistant transconjugants contained pUB307::RSF1596 cointegrates, as expected, conferring kanamycin, tetracycline and carbenicillin resistance but not chloramphenicol resistance. Transconjugants selected on chloramphenicol, however, always displayed carbenicillin resistance in addition to kanamycin and tetracycline resistance, indicating that the recombinant plasmids in these cells had arisen by two independent transposition events inolving all three replicons in the donor cell, creating cointegrates which possess three replication origins, and three copies of $\mathrm{Tn} 596$ originating on RSF1596. These recombinants have proved to be unstable, and after a period of time, chloramphenicol resistance is lost if no selection is maintained. In no case was chloramphenicol resistance found linked to kanamycin or tetracycline resistance independently of cabenicillin resistance.

\section{Recombination between $p U B 307$ and either pUB3032 or pUB3033}

Having established the ability of pUB3032 and pUB3033 to express their tnpA genes, the ability of pUB3032 and pUB3033 to mediate plasmid fusions was tested. The IncP plasmid pUB307 was introduced by conjugation into $E$. coli UB5201(pUB3032) and UB5201(pUB3033). The double plasmid strains were stored for 3 weeks on Dorset egg slopes to allow accumulation of fusion products, and were then mated with $E$. coli UB2272. Plasmid pUB307 transferred to $E$. 
Table 2. Transfer frequencies of pBR322, pUB3032 and pUB3033 markers mobilized by R388

\begin{tabular}{|c|c|c|}
\hline \multirow[b]{2}{*}{ Plasmids in donor strain } & \multicolumn{2}{|c|}{$\begin{array}{l}\text { Relative transfer } \\
\text { frequency }\end{array}$} \\
\hline & $\mathrm{Cm} / \mathrm{Tp}$ & $\mathrm{Cb} / \mathrm{Tp}$ \\
\hline $\begin{array}{l}\text { R388, pBR322, pUB3032 } \\
\text { R388, pBR322, pUB3032 }\end{array}$ & $\begin{array}{r}6 \times 10^{-8} \\
<1 \times 10^{-8}\end{array}$ & $\begin{array}{l}2 \times 10^{-7} \\
4 \times 10^{-7}\end{array}$ \\
\hline $\begin{array}{l}\text { R388, pBR322, pUB3033 } \\
\text { R388, pBR322, pUB3033 }\end{array}$ & $\begin{array}{l}3 \times 10^{-7} \\
2 \times 10^{-7}\end{array}$ & $\begin{array}{l}3 \times 10^{-7} \\
4 \times 10^{-7}\end{array}$ \\
\hline
\end{tabular}

coli UB2272 at a frequency of about $10^{-1}$ as was found in the crosses described above, while chloramphenicol resistance was transferred at a frequency of $2.9 \times 10^{-7}$ when the donor plasmid was pUB3032 and $5.5 \times 10^{-7}$ when it was pUB3033. These results indicated linkage of the pUB3032 and pUB3033 chloramphenicol resistance genes to pUB307 since neither donor plasmid can replicate in $E$. coli UB2272. Transfer experiments using several of these transconjugants, in turn, as donors confirmed the linkage. Since no recombination between the chloramphenicol resistance determinant of pACYC184 and pUB307 was demonstrated in similar experiments, we concluded that the recombination observed was as a consequence of the residual $\operatorname{Tn} A$ sequences carried on pUB3032 and pUB3033.

\section{Recombination between $R 388$ and pUB3032, pUB3033 or pBR322}

Plasmids pUB3032 and pUB3033 carry the left-hand end of $\operatorname{Tn} A$, incorporating the left-hand IR sequence and an intact copy of the $\operatorname{tnp} A$ gene. Their ability to mediate recombinations in trans was also assessed. Plasmid pBR322 is a non-conjugative plasmid that carries the righthand IR sequence and the bla gene of $\operatorname{Tn} A$ (Fig. 1). R388 is a conjugative IncW plasmid that confers resistance to sulphonamides and trimethoprim, carries no $\operatorname{Tn} A$ sequences, and is unable to mobilize pBR322 or pACYC184 (data not shown). Plasmids pUB3032 and pUB3033 were introduced separately into $E$. coli UB5201(pBR322) by transformation. Plasmid R388 was then introduced, by conjugation, into the transformants. The progeny were held on Dorset egg slopes for 4 weeks, after which time they were mated, on nutrient agar, with $E$. coli JC6310. The transfer frequencies measured are presented in Table 2 . In these experiments R388 transferred at a frequency of approximately $10^{-1}$. Transconjugants were tested to determine which nonselected resistance determinants had been co-inherited; all of the 24 carbenicillin resistant transconjugants tested were also resistant to tetracycline and trimethoprim, but not to chloramphenicol, indicating that pBR322 alone had been mobilized by R388 in the presence of transposase. All of the 18 transconjugants selected for the transfer of chloramphenicol resistance displayed resistance to trimethoprim, indicating recombination between either pUB3032 or pUB3033 and R388. One chloramphenicol resistant transconjugant was also resistant to carbenicillin and tetracycline in addition to trimethoprim. In subsequent transfer experiments with this transconjugant as donor, all antibiotic resistance determinants transferred in the initial mating remained linked, irrespective of which was chosen to select for transfer of the putative fusion product. This recombinant plasmid presumably arose as the product of two separate recombination events involving all three plasmids.

To test genetic linkage of the resistance markers in the presumed fusions, four representatives of each type of transconjugant were mated, on solid medium, with E. coli UB5201. Mating products were selected on supplemented minimal medium with nalidixic acid and trimethoprim. In addition to trimethoprim resistance, all transferred either chloramphenicol resistance or carbenicillin and tetracycline resistance, as appropriate, indicating recombination of R388 with pUB3032, pUB3033 or pBR322. Two independent isolates of the 12 clones tested failed to exhibit sulphonamide resistance as normally conferred by $R 388$, indicating insertion in this gene. 
Table 3. Transfer of pUB2280, pUB2284, pUB3032, pUB3033 and pUB3078 markers mobilized by $p U B 307$

Mobilization frequencies were calculated as the ratio of the frequency of inheritance of the appropriate non-conjugative marker to the total frequency of inheritance of resistance to kanamycin, the selection imposed to measure the transfer of pUB307. The plasmid host strain was E. coli UB5201.

Plasmids in donor strain
pUB2280, pUB307
pUB2284, pUB307
pUB3032, pUB2280, pUB307
pUB3033, pUB2280, pUB307
pUB3032, pUB2284, pUB307
pUB3033, pUB2284, pUB307
pUB3032, pUB3078, pUB307
pUB3033, pUB3078, pUB307

Plasmids in donor strain
Relative transfer frequencies

$\begin{array}{cr}\mathrm{Cm} / \mathrm{Km} & \mathrm{Tp} / \mathrm{Km} \\ - & <2 \times 10^{-8} \\ - & 4 \times 10^{-8} \\ 2 \times 10^{-6} & 4 \times 10^{-7} \\ 4 \times 10^{-6} & 1 \times 10^{-6} \\ 2 \times 10^{-5} & 1 \times 10^{-5} \\ 7 \times 10^{-6} & 1 \times 10^{-7} \\ 1 \times 10^{-6} & <3 \times 10^{-7} \\ 8 \times 10^{-7} & <1 \times 10^{-7}\end{array}$

\section{Recombination between $p U B 307$ and either $p U B 2280$ or pUB2284 requires TnA IR sequences}

In a parallel set of experiments, the ability of the IncP plasmid pUB307 to mobilize pUB2280, pUB2284 and pUB3078 (Fig. 1) was tested. In this experimental set, pUB2280, pUB2284 or pUB3078 was together with either pUB3032 or pUB3033 and pUB307 in the donor strain. Plasmids pUB2280, pUB2284 and pUB3078 are non-self-transmissible R388 derivatives which confer resistance to trimethoprim. Plasmid pUB2280 carries the left-hand $1000 \mathrm{bp}$ of $\operatorname{Tn} A$, while pUB2284 carries the right-hand $450 \mathrm{bp}$ of $\operatorname{Tn} A$ (see Fig. 1). Plasmid pUB3078 carries no sequence derived from $\operatorname{Tn} A$. None of these plasmids is normally mobilized by pUB307 (Table 3 ). The six donor strains were individually mated, on nutrient agar, with UB2272. Transconjugants were selected separately with kanamycin, chloramphenicol and trimethoprim (Table 3). All crosses displayed transfer of resistance to kanamycin and to chloramphenicol. While transfer of trimethoprim resistance was observed from strains carrying pUB2280 and pUB2284, no transfer of trimethoprim resistance from strains carrying pUB3078 was detected.

On testing for the acquisition of non-selected markers, it was demonstrated that if the initial selection imposed was for the transfer of trimethoprim resistance, this was always accompanied by the co-transfer of kanamycin or of tetracycline, usually both, implying recombination of pUB307 with either pUB2280 or pUB2284. Similarly, if chloramphenicol resistance was employed as the primary selection, kanamycin or tetracycline resistance, usually both, were acquired, indicating recombination between pUB307 and either pUB3032 or pUB3033. In this set of experiments, no products carrying markers derived from all three plasmid types were seen. Finally, when these transconjugants were, in turn, outcrossed to another strain of $E$. coli (UB5201), all the markers acquired in the first mating were transferred as linked sets, irrespective of which marker was used for the primary selection. All recombinant plasmids transferred with frequencies between $10^{-2}$ and $10^{-3}$ per donor.

\section{Restriction endonuclease analysis of plasmid recombinants}

Recombination products were subjected to restriction endonuclease analysis. Three recombinants of pBR322 and R388 were analysed in detail, as were one each of the recombinants of R388 and either pUB3032 or pUB3033. The enzymes employed in this analysis included BamHI, Bg/II, EcoRI, HindIII and PstI, and these were used both singly and in combination. Fig. 2(a) illustrates the results for an R388: :pUB3033 recombinant, pUB3073, while Fig. $2(b)$ indicates the molecular configuration of the recombinant that was deduced from the data. In all cases where a detailed analysis of the fusion products was undertaken, the recombinant plasmids carried the appropriate number of restriction sites consistent with simple plasmid fusions. Furthermore, in all cases examined to date the junction between R388 and the mobilized plasmid carrying the $\operatorname{Tn} A$ IR sequence involves the same region of the mobilized 


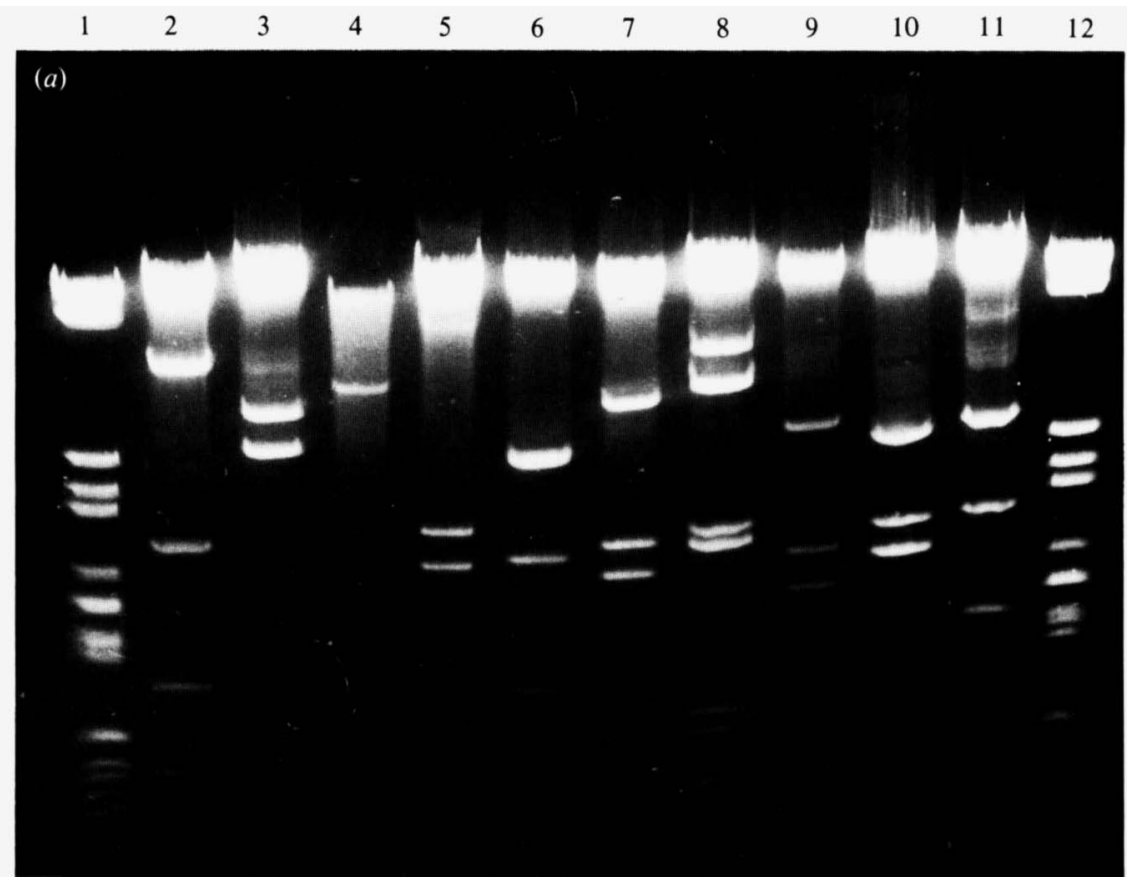

(b)

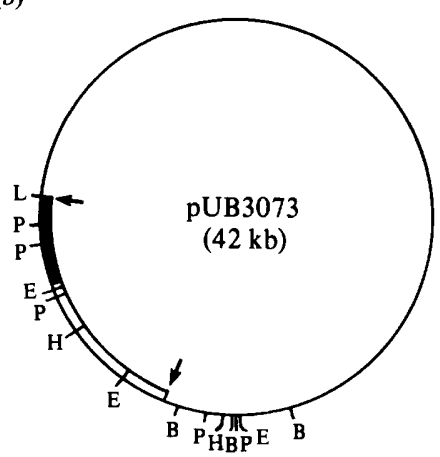

Fig. 2. (a) Agarose gel $(0 \cdot 8 \%)$ of fragments of pUB3073 generated by restriction endonuclease digestion. Tracks 1 and 12 are $\lambda B g /$ fragments used as size standards. The enzymes employed were: Pst I (track 2); EcoRI (track 3); HindIII (track 4); BamHI (track 5); PstI + EcoRI (track 6); PstI + HindIII (track 7); PstI + BamHI (track 8);EcoRI + HindIII (track 9); EcoRI + BamHI (track 10); and HindIII + Bam HI (track 11). (b) Map deduced from the restriction endonuclease data presented in (a). The double lines denote pUB3033 sequences and the thin line denotes R388 sequences. The $\operatorname{Tn} A$ sequence is shown as a bold line. Arrows denote the points of recombination. L, left-hand IR sequence B, BamHI: E, EcoRI; H, HindIII; P, PstI.

plasmid, namely that accommodating the IR sequence of Tn 802 , while the R 388 junction varies from one recombinant to another (Fig. 2). To ensure that the remaining fusion products conformed to the same general pattern, each recombinant isolated was examined with a HindIII $+E c o$ RI double digestion. The results were totally consistent with the above findings.

Restriction endonuclease analysis of the recombinants of pUB307 and either pUB2280, pUB3032 or pUB3033 showed them also to be simple replicon fusions. Again the point of fusion in the target replicon, in this case pUB307, varied from one recombinant to another, while the point of fusion on the mobilized plasmid appeared to be site-specific, consistent with the 


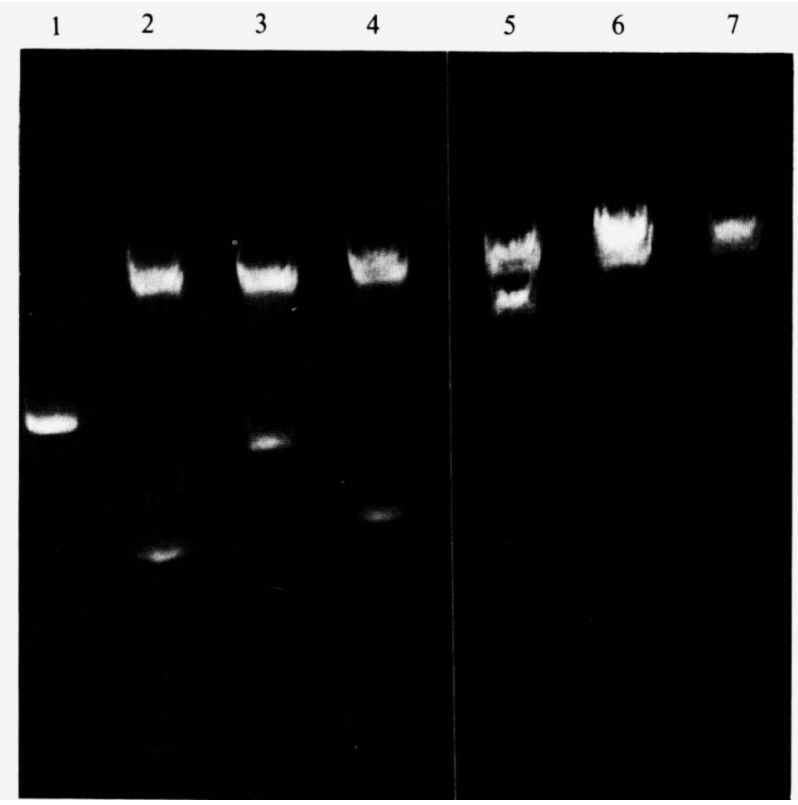

Fig. 3. Agarose gel $(0.8 \%)$ of restriction endonuclease fragments of R388/pBR322 recombinants. Fragments were generated by HindIII + EcoRI double digestion. Track 1, pBR322; tracks 2-6, R388/pBR322 recombinants; track 7, R388.

involvement of the $\operatorname{Tn} A$ IR sequence. Major duplications of, or deletions of sequences from, any of the parental plasmids have not been observed, although the resolution of this analysis is not sufficient to determine whether small duplications or deletions have occurred.

The molecular analysis of the fusion products revealed that insertions occur at diverse sites in R388 (Fig. 3) and pUB307 (data not shown). Interestingly, fusion products isolated independently from the same original donor strain display a marked tendency to give an identical pattern of restriction fragments, implying a high degree of sibling isolation, in which case the frequencies calculated for fusion formation are upper limits.

In comparison to the other 'single-ended' $\mathrm{Tn} A$ fusions described, fusions between pUB2284 and pUB307 were more difficult to demonstrate, and although some fusion products apparently incorporate the entire pUB2284 sequence, others do not. In these cases, although all the pUB307 sequences could be accounted for, not all of the pUB2284 sequence was present [indicated by the observation that the $B g / I$ site of pUB2284 (Fig. 1) was not present on the fusion product (data not shown)], implying either premature termination of the replication of this plasmid during the fusion process, or secondary deletion of part of the pUB2284 sequence after fusion of the entire plasmid with pUB307.

\section{DISCUSSION}

$\operatorname{Tn} A$ belongs to a family of transposons which share similar structures and transposition functions (Kleckner, 1981; Schmitt et al., 1981; Grinsted et al., 1982; Diver et al., 1983; Heffron, 1983). Recently it has been reported that derivatives of two members of this family, Tn21 (Avila et al., 1984) and Tn172I (Motsch \& Schmitt, 1984), possessing only one IR sequence, can, when provided with appropriate transposase, promote plasmid fusions, albeit at a lower frequency than transposition of the intact element. In the case of $\operatorname{Tn} 21$, the frequency of replicon fusion is about 10 -fold lower than normal transposition; with $\mathrm{Tn} 1721$, transposition of the intact transposon is about 100 times more frequent than replicon fusions mediated by one end of the element. 
The results reported in this paper indicate that the transposition system of $\operatorname{Tn} A$ can also mediate plasmid fusions via a single end of the element. [Since the work described here was completed Arthur et al. (1984) have also reported that $\operatorname{Tn} A$ can mediate one-ended plasmid fusions.] Either end of $\operatorname{Tn} A$ may be utilized, as witnessed by fusions involving pUB3032, pUB3033 and pUB2280, which all carry the left-hand end of $\operatorname{Tn} A$, and those involving pBR322 and pUB2284, which both carry the right-hand end of $\operatorname{Tn} A$. That one end of $\operatorname{Tn} A$ is necessary for recombination is demonstrated by the inability of pUB3078 to form fusions with pUB307 under conditions in which pUB2280 and pUB2284 did so. Furthermore, the fact that pBR322, pUB2280 and pUB2284 underwent fusion with pUB307 only in the presence of either pUB3032 or pUB3033 indicates that the recombination requires the tnp $A$ gene product.

The frequency of $\operatorname{Tn} A$-mediated one-ended recombinations is at least 1000 -fold lower than the frequency of transposition of $\mathrm{Tn} 596$ in a comparable system, i.e. when complemented with either pUB3032 or pUB3033. Heffron et al. (1977) reported a 1000-fold reduction in the mobilization of ampicillin resistance on plasmids carrying $\operatorname{Tn} A$ elements from which the lefthand IR sequence has been lost. However, the transposase gene was provided on a plasmid carrying $\operatorname{Tn} A$ with a deletion in the bla and $t m p R$ genes but with both IR sequences intact. No analysis of the products was reported; our results suggest that the most likely method of mobilizing the bla gene in these systems would have been by a double transposition event, such as we observed when assessing the ability of pUB3032 and pUB3033 to complement transposition of Tn596, and not by a 'single-ended' plasmid fusion.

In the systems we have used to study recombinations mediated by a single end of $\operatorname{Tn} A$, transposase production was derepressed, since the deletions giving rise to pUB3032 and pUB3033 caused the loss of the tnpR gene. Additionally, the transposase gene was present on a multi-copy plasmid (a derivative of pACYC184). Yet, recombinations could not be demonstrated in every cell-line tested, even though these were apparently identical, indicating that in comparison with the normal transposition of $\operatorname{Tn} A$, recombinations mediated by one end of the element are rare events. The demonstration that from a single donor strain there is an apparently high probability of sibling isolation leads us to the conclusion that the frequency of plasmid fusion must be lower than the apparent frequency observed.

The phenomenon of plasmid fusions mediated by a single end of $\operatorname{Tn} A$ is not confined to a single plasmid type, since both the IncP plasmid pUB307 and the IncW plasmid R388 are capable of mobilizing various non-conjugative plasmids carrying either the left- or right-hand IR sequence of $\operatorname{Tn} A$ when transposase is provided in cis or in trans, as appropriate. Thus the data presented here are consistent, in general, with the observation that plasmids incorporating a single IR sequence derived from this family of transposons are capable of fusing with other replicons, providing that the appropriate transposase function is supplied. This type of recombination is independent of the host recombination system since, in these experiments, a rec $A$ cell was used as the donor strain. It is also independent of the transposon-encoded sitespecific recombination system since the complementing system is $\operatorname{tn} p R$.

In cells carrying RSF1596, which carries Tn596, a Tn $A$ derivative with a small internal deletion but with both IR sequences intact (Heffron et al., 1977), and either plasmid pUB3032 or pUB3033, chloramphenicol resistance encoded by either pUB3032 or pUB3033 was only ever seen to be mobilized by pUB307 via transposition cointegrates generated by Tn596; simple fusions between either pUB3032 or pUB3033 and pUB307 were never detected in these particular experiments, even though we would have expected to detect these events with the number of chloramphenicol resistant transconjugants examined. Thus 'normal' transposition would appear to have suppressed one-ended recombinations.

It is worth noting that whereas pUB3032 and pUB3033 mediated, with reasonable ease, plasmid fusions of both themselves and either pBR322 or pUB2280 with either R388 or pUB307, it was much more difficult to detect fusions between pUB307 and pUB2284, mediated by either pUB3032 or pUB3033, in that plasmid recombination occurred in less than half of the cell lines constructed. The reason for this is not known, but may reflect the somewhat larger size of pUB2284, a factor that may also be relevant to the isolation of recombinants that incorporated less than the whole of pUB2284. 
The finding that the $\operatorname{tn} p A$ gene product of $\operatorname{Tn} A$ can mediate inter-replicon recombinations via a single IR sequence appears to be more consistent with an asymmetric or processive model of transposition (Galas \& Chandler, 1981; Grindley \& Sherratt, 1979; Harshey \& Bukhari, 1981) than with a symmetric model (Arthur \& Sherratt, 1979; Shapiro, 1979), and, indeed, it has been argued that the generation of recombinants mediated by a single IR sequence of $\operatorname{Tn} 21$ provides evidence in support of asymmetric models of transposition, the corollary being that symmetric models must be incorrect (Avila et al., 1984). However, Motsch \& Schmitt (1984) point out that the low frequency of replicon fusion and the apparent inability of the system to form cointegratetype intermediates leaves open the possibility that different processes may be reponsible for the two types of recombination. In general, we would concur with the latter point of view, since our observations point to differences between recombinations mediated by a single end of $\operatorname{Tn} A$ and the transposition of a complete $\operatorname{Tn} A$ element. The one-ended recombinations studied here are different from normal transposition systems both in form and in end-product. The former recombination events, mediated by $\operatorname{Tn} A$ components, are rare, and do not transpose a discrete, defined element, while an element bounded by $\operatorname{Tn} A$ IR sequences, present as inverted repeats, does transpose as a discrete sequence, and at a frequency which is several orders of magnitude greater. It is, therefore, difficult to escape the conclusion that the presence of the second IR sequence as an inverted repeat not only helps to define the element, but also plays a significant role in determining its transposition frequency. The mechanism of recombination mediated by a single IR sequence of $\operatorname{Tn} A$, and of true $\operatorname{Tn} A$ transposition, although involving common components, are quite clearly and necessarily different in several aspects, so there is no compelling reason to believe that the initiation mechanisms must be identical. Hence, although the recombinations reported here are likely to be mediated by a mechanism akin to the asymmetric models of transposition, this does not preclude a symmetric mechanism for true transposition.

This work was supported by a grant from the Medical Research Council (UK) to P.M.B. We would like to thank Dr Helen Dodd for allowing us to use her strains, and for her helpful discussion of this work. Thanks are also due to Dr John Grinsted for providing access to unpublished data. The expert technical assistance of Mr David Bennett and Mr Paul Duckett is gratefully acknowledged.

\section{REFERENCES}

Arthur, A. \& SherratT, D. J. (1979). Dissection of the transposition process: a transposon-encoded site-specific recombination system. Molecular and General Genetics 175, 267-274.

Arthur, A., Nimmo, E., Hettle, S. \& Sherratt, D. (1984). Transposition and transposition immunity of transposon $\mathrm{Tn} 3$ derivatives having different ends. EMBO Journal 3, 1723-1730.

Avila, P., De la Cruz, F., Ward, E. \& Grinsted, J. (1984). Plasmids containing one inverted repeat of Tn 21 can fuse with other plasmids in the presence of Tn21 transposase. Molecular and General Genetics 195, 288-293.

BennetT, P. M. \& Richmond, M. H. (1976). Translocation of a discrete piece of deoxyribonucleic acid carrying an $a m p$ gene between replicons in Escherichia coli. Journal of Bacteriology 126, 1-6.

BenNett, P. M., GRINSTED, J. \& Richmond, M. H. (1977). Transposition of $\operatorname{Tn} A$ does not generate deletions. Molecular and General Genetics 154, 205211.

Birnboim, H. C. \& Doly, J. (1979). A rapid alkaline extraction procedure for screening recombinant plasmid DNA. Nucleic Acids Research 7, 1513-1523.
Bolivar, F., Rodriguez, R. L., Greene, P. J., Betlach, M. C., Heynecker, H. C., Boyer, H. W., Crosa, J. H. \& Falkow, S. (1977). Construction and characterization of new cloning vehicles. II. A multipurpose cloning system. Gene 2, 95-113.

Chou, J., LemauX, P. G., Casadaban, M. J. \& Cohen, S. N. (1979). Transposition protein of Tn3: identification and characterisation of an essential repressorcontrolled gene product. Nature, London 282, 801806.

Cohen, S. N., Chang, A. C. Y. \& Hsu, L. (1972). Non chromosomal antibiotic resistance in bacteria: genetic transformation of Escherichia coli by R-factor DNA. Proceedings of the National Academy of Sciences of the United States of America 69, 21102114.

DatTA, N. \& Hedges, R. W. (1972). Trimethoprim resistance conferred by $W$ plasmids in enterobacteriaceae. Journal of General Microbiology 72, 349355.

Diver, W. P., Grinsted, J., Fritzinger, D. G., Brown, N. L., Altenbuchner, J., Rogowsky, P. \& SCHMITT, R. (1983). DNA sequences of and complementation by the $\operatorname{tnpR}$ genes of $\operatorname{Tn} 21, \mathrm{Tn} 501$ and 
Tn 1721, Molecular and General Genetics 191, 189 193.

DoDD, H. M. \& BENNETT, P. M. (1983). R46 encodes a site-specific recombination system interchangeable with the resolution function of $\operatorname{Tn} A$. Plasmid 9, 247261.

Galas, D. J. \& Chandler, M. (1981). On the molecular mechanism of transposition. Proceedings of the National Academy of Sciences of the United States of America 78, 4858-4862.

Gill, R., Heffron, F., Dougan, G. \& Falkow, S. (1978). Analysis of sequences transposed by complementation of two classes of transposition-deficient mutants of Tn3. Journal of Bacteriology 136, 742-756.

Grindley, N. \& SherratT, D. J. (1979). Sequence analysis of IS1 insertion sites. Cold Spring Harbor S!mposia on Quantitative Biology 43, 1257-1261.

Grinsted, J., BennetT, P. M., Higginson, S. \& Richmond, M. H. (1978). Regional preference of insertion of Tn501 and Tn802 into RPl and its derivatives. Molecular and General Genetics 166, 313320 .

Grinsted, J., De La Cruz, F., Altenbuchner, J. \& SCHMITT, R. (1982). Complementation of transposition of $\operatorname{tnp} A$ mutants of $\operatorname{Tn} 3, \operatorname{Tn} 21, \operatorname{Tn} 501$ and Tn1721. Plasmid 8, 276-286.

HARShey, R. M. \& BUKharI, A. (1981). A mechanism of DNA transposition. Proceedings of the National Academy of Sciences of the United States of America 78, 1090-1094.

HefFron, F. (1983). Tn 3 and its relatives. In Mobile Genetic Elements, pp. 223-260. Edited by J. A. Shapiro. New York: Academic Press.

Heffron, F., Beddinger, P., Champoux, J. J. \& Falkow, S. (1977). Deletions affecting the transposition of an antibiotic resistance gene. Proceedings of the National Academy of Sciences of the United States of America 74, 702-706.

Heritage, J. \& Bennett, P. M. (1984). The role of Tn $A$ transposase in transposition immunity. Plasmid 12. 218-221.
Humphries, G. O., Willshaw, G. A., Smith, H. R. \& ANDERSON, E. S. (1976). Mutagenesis of plasmid DNA with hydroxylamine: isolation of mutants of multicopy plamids. Molecular and General Genetics 145, 101-108.

Jenkins, S. T. \& BennetT, P. M. (1978). Effect of mutations in deoxyribonucleic acid repair pathways on the sensitivity of Escherichia coli K-12 strains to nitrofurantoin. Journal of Bacteriology 125, 12141216.

KLECKNER, N. (1981). Transposable elements in prokaryotes. Annual Review of Genetics 15, 341-404.

Motsch, S. \& SchmitT, R. (1984). Replicon fusion mediated by a single-ended derivative of transposon Tn1721. Molecular and General Genetics 195, 281 287

Novick, R. P., Clowes, R. C., Cohen, S. N., Curtiss, R., DatTa, N. \& Falkow, S. (1976). Uniform nomenclature for bacterial plasmids: a proposal. Bacteriological Revien's 40, 168-189.

Robinson, M. K., BEnNett, P. M. \& Richmond, M. H. (1977). Inhibition of $\operatorname{Tn} A$ translocation by $\operatorname{Tn} A$. Journal of Bacteriology 129, 407-414.

SChmitt, R., Altenbuchner, J. \& Grinsted, J (1981). Complementation of transposition functions encoded by transposons $\mathrm{Tn} 501(\mathrm{Hg})$ and $\mathrm{Tn} 1721$ (Tc'). In Molecular Biology, Pathogenicity, and Ecology of Bacterial Plasmids. pp. 359. 370. Edited by B. Levy, R. C. Clowes \& E. C. Koenig. New York: Plenum.

Shapiro, J. (1979). Molecular model for the transposition and replication of bacteriophage mu and other transposable elements. Proceedings of the National Academy of Sciences of the United States of America 76, 1933-1937.

Wallace, L. J., Ward, J. M. \& Richmond, M. H. (1981). The location of sequences of $\operatorname{Tn} A$ required for the establishment of transposition immunity. Molecular and General Genetics 184, 80-86. 